\title{
Selection of model for the numerical study of the convective jet problem
}

\author{
Juliya Kareeva $^{1 *}{ }^{[0000-0002-9497-349 X]}$, Rustam Gabdrafikov ${ }^{10000-0002-6806-1868]}$, and Maria \\ Chukhlova ${ }^{1}$ [0000-0002-1678-8168] \\ ${ }^{1}$ Kazan State University of Architecture and Engineering, 420043, Zelenaya st., Kazan, Russia
}

\begin{abstract}
The heat released by local exhaust ventilation is one of the most common hazards emitted during various industrial processes in industrial buildings. This work solves problems in order to find the numerical solution model that most adequately describes the development of a free convective jet above a flat heat source and a convective jet near the side hood located above the heat source. Various turbulence models and options of wall functions are considered for application in the study of a free convective jet. The data showed that the closest to theoretical results are those obtained when using the standard k-e model together with standard wall functions.
\end{abstract}

Keywords: numerical method, turbulence models, wall functions, convective jet, local exhaust ventilation, side hood.

\section{Introduction}

The heat released by local exhaust ventilation is one of the most common hazards emitted during various processes in industrial buildings. When the air temperature in a room deviates from the normal one $\left(23-25^{\circ} \mathrm{C}\right.$, at which a person's productivity is assumed to be $100 \%$, and the physical condition is assessed as the norm), the productivity and well-being of a person decrease.

Local exhaust ventilation is used together with general exchange ventilation to provide the most efficient operation of the ventilation system in rooms with heat surplus. The main types and designs of local exhaust devices were presented and systematized in [1-3].

To determine the most efficient local ventilation system, it is important to know the characteristics of the harmful substances spreading in the room as a result of the production process. Some works investigate the characteristics of a free convective jet arising at a vertical plate and a horizontal heat source [4-7].

Several authors considered the efficiency of collecting dust particles by local exhaust hoods. [8-11]. In this articles authors studied the vortex zones near the local exhaust hoods and their influence to the efficiency of collecting. The comparison of the efficiency of collecting of the side hood when capturing gas and heat emissions is given in the articles $[12,13]$.

\footnotetext{
* Corresponding author: jkareeva2503@gmail.com
} 
The works [14-16] consider numerical modeling of the operation of local exhaust devices when working together with supply jets.

This study aims to select a model for the numerical solution that most adequately describes the development of a free convective jet above a flat heat source and a convective jet near a side hood located at a certain height above the heat source. To achieve this goal, the task is solved in two stages:

- Assessing the influence of turbulence models on the characteristics of a free convective jet;

- Assessing the influence of wall functions on the characteristics of a convective jet developing near the side hood.

\section{Methods}

The problem is solved numerically using the Fluent software package [17]. Fig. 1 shows the considered geometries of the problems being solved.
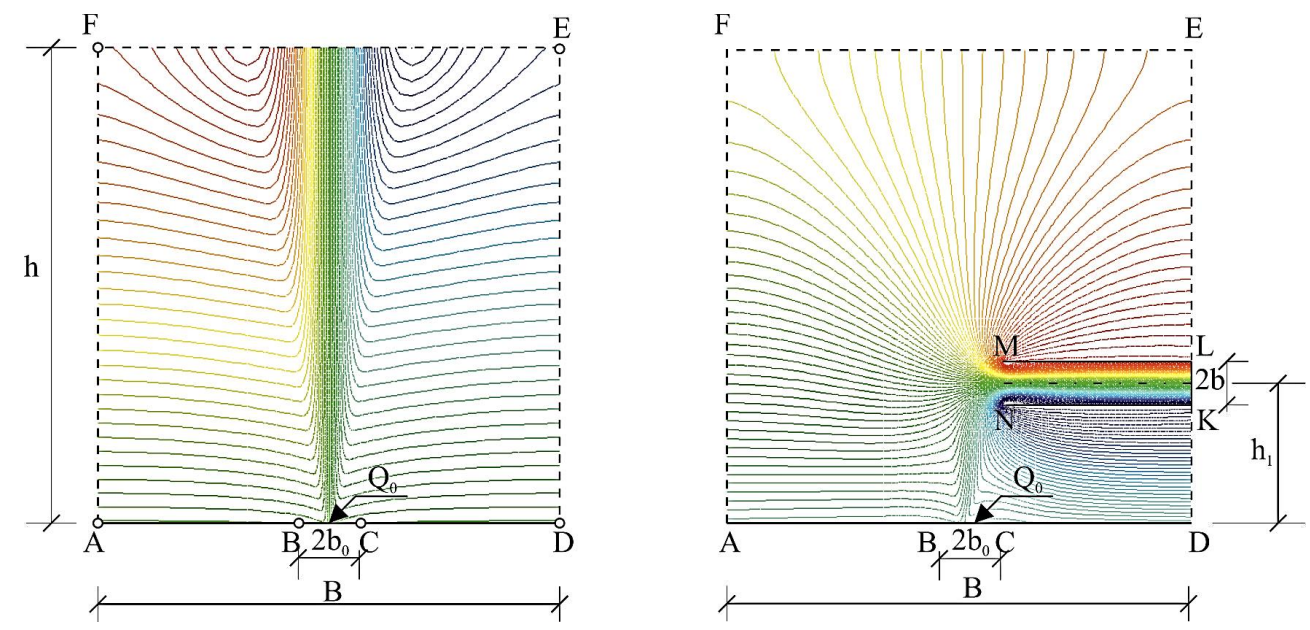

Fig. 1 a) Free convective jet; b) Convective jet near the side hood.

At the first stage, the problem of natural convection near a flush-mounted heat source is considered. The size of the heat source is $2 \mathrm{~b}_{0}=0.2 \mathrm{~m}$, its power is $\mathrm{Q}_{0}=400 \mathrm{~W}$, the studied area has the following dimensions: width $2 \mathrm{~B}=2.2 \mathrm{~m}$; height $\mathrm{H}=2.2 \mathrm{~m}$.

The problem considers the effect of application of different turbulence models presented in the Fluent software package on jet characteristics (axial velocity and excess temperature on the convective jet axis). To close the Reynolds-averaged Navier-Stokes equations, the following equations of turbulence models are used: with one equation (Spalart-Allmares model), with two equations («standard» $\mathrm{k}-\varepsilon$ (KES), RNG k- $\varepsilon, \mathrm{k}-\varepsilon$ realizable and «Reynolds stress» RSM).

At the second stage of the study, a side hood with a width of $2 \mathrm{~h}=0.2 \mathrm{~m}$ with a constant suction speed $u_{0}=0.7 \mathrm{~m} / \mathrm{s}$ (Fig. $1 \mathrm{~b}$ ) is considered. It is located at a height of $\mathrm{h} 1=0.75 \mathrm{~m}$. The geometry of the studied area is the same as in stage 1 . The average suction rate is determined based on the conditions presented in [18]:

$$
\bar{u}_{a v}=0.032\left(\frac{Q_{c}}{b}\right)^{1 / 3} \sqrt{1+1.58\left(\frac{h_{1}}{b}-0.2\right)}
$$

where $Q_{c}$ is the convective part of heat release. 
The change in flow characteristics calculated using different wall functions is considered. The Fluent software includes two main models - using wall functions (Standard Wall Functions (SWF) and Non-equilibrium Wall Functions (NWF)) and Enhanced Wall Treatment (EWT). When using wall functions in the area near solid walls, special semiempirical equations are solved to relate the values on the wall and in the flow core, which are obtained by solving the Reynolds equations of motion.

This study adopts the following boundary conditions:

- LK (air outlet) - Velocity inlet: uniform velocity profile, velocity is directed along the normal to the boundary: $u_{0}=$ const; $k=0 ; \varepsilon=0$;

$-\mathrm{AB}, \mathrm{CD}, \mathrm{AF}, \mathrm{FE}, \mathrm{ED}$ (free flow boundaries) - Pressure Outlet: excess pressure $\Delta \mathrm{p}=$ 0 ; velocity is directed along the normal to the boundary $u^{-}=u_{n}, d k / d n=0, d \varepsilon / d n=0$;

$-\mathrm{BC}$, ML and LK (impermeable walls) Wall: $u=0,\left(d u_{n}\right) / d n=0$; where $\mathrm{d} / \mathrm{dn}$ are derivatives along the normal to the boundary.

As a result of the solution, a change in the axial parameters of the convective jet was obtained. The results are presented in the dimensionless form.

To select the most adequate model for the numerical solution, the results obtained were compared with the known theoretical data for a free convective jet [19, 20].

\section{Results and discussion}

The streamlines obtained using different versions of turbulence models show a similar qualitative nature of the flow of a free convective jet arising at a heat source (Fig.1a). An exception is the $k-w$ model. When using this model, the jet turned out to be curved. So, this model is inadequate and cannot be used to solve problems of natural convection (Fig.2a).

To compare the results obtained numerically, we used the expressions for determining the axial velocity (2), presented in [19] and equation (3) [20]:

$$
\begin{gathered}
\left.\bar{u}_{y}=\frac{u_{y}}{\sqrt[3]{\left(g Q_{c} / c_{p} \rho_{\infty} T_{\infty}\right)}}=\sqrt[3]{\frac{1+\operatorname{Pr}_{t}}{4 \operatorname{Pr}_{t}}-1 / 3} y^{1 / 3}\left(\sqrt{\frac{3}{2}} \cdot \frac{1}{c \bar{y}}\right)\right)^{1 / 3} \\
\bar{u}_{y}=\frac{u_{y}}{\sqrt[3]{\left(g Q_{c} / c_{p} \rho_{\infty} T_{\infty}\right)}}=\frac{0,065 Q_{c}^{1 / 3}}{\sqrt[3]{\left(g Q_{c} / c_{p} \rho_{\infty} T_{\infty}\right)}}
\end{gathered}
$$

where $\bar{u}_{y}$ is the dimensionless axial velocity; $c_{p}$ is the air heat capacity, $\rho_{\infty}$ is the air density at infinity for the ambient air temperature $\mathrm{T}_{\infty}, \operatorname{Pr}_{t}$ is the turbulent Prandtl number (0.85), $\bar{y}=y / b_{0}$ is the dimensionless coordinate.

The numerical calculations showed that the convective and radiation components of heat release are different when calculated using different models of turbulence (Table 1). The convective component was further used in calculations (expressions (2) and (3)).

Table 1. Convective and radiation components of heat release.

\begin{tabular}{|c|c|c|c|c|c|}
\hline $\begin{array}{c}\text { Turbulence } \\
\text { model }\end{array}$ & k- $\varepsilon$ standard & $\begin{array}{c}\mathrm{k}-\varepsilon \\
\text { realizable }\end{array}$ & $\mathrm{k}-\varepsilon$ RNG & RSM & SA \\
\hline $\mathrm{Q}_{\mathrm{rad}}$ & 51.82 & 45.27 & 53.35 & 43.7 & 54.13 \\
\hline $\mathrm{Q}_{\mathrm{conv}}$ & 28.18 & 34.73 & 26.65 & 36.3 & 25.87 \\
\hline
\end{tabular}



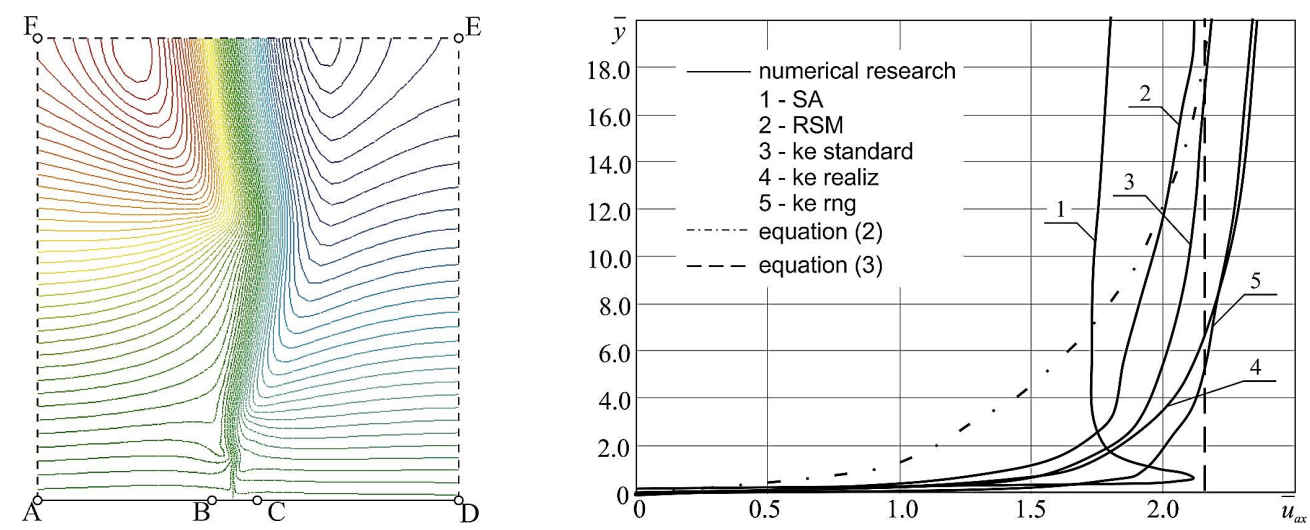

Fig. 2. a) Flow streamlines for $k-w$ turbulence model; b) The change in axial velocity along the jet height calculated using different turbulence models.

Figure $2 \mathrm{~b}$ shows the change in the jet axial velocity calculated using different turbulence models. The curves obtained from expressions (2) and (3) are also shown.

At a distance of about $12 b_{0}$, the jet has an initial section. In this case, equation (3) does not make sense, since it is suitable only for the main section of the jet. In the main section, the most adequate results are obtained using the k- $\varepsilon$ standard and RSM models.

Figure 3 shows changes in dimensionless excess temperature along the jet length obtained numerically and using expression (4) [20].

$$
\Delta \bar{t}_{y}=\frac{0,064 Q_{c}^{2 / 3} y^{-1}}{\Delta t_{\infty}}
$$

where $\Delta \bar{t}_{y}$ is the dimensionless excess temperature on the jet axis.

The results obtained numerically are close to each other. The closest value to theoretical data is obtained when using the standard k- $\varepsilon$ model.

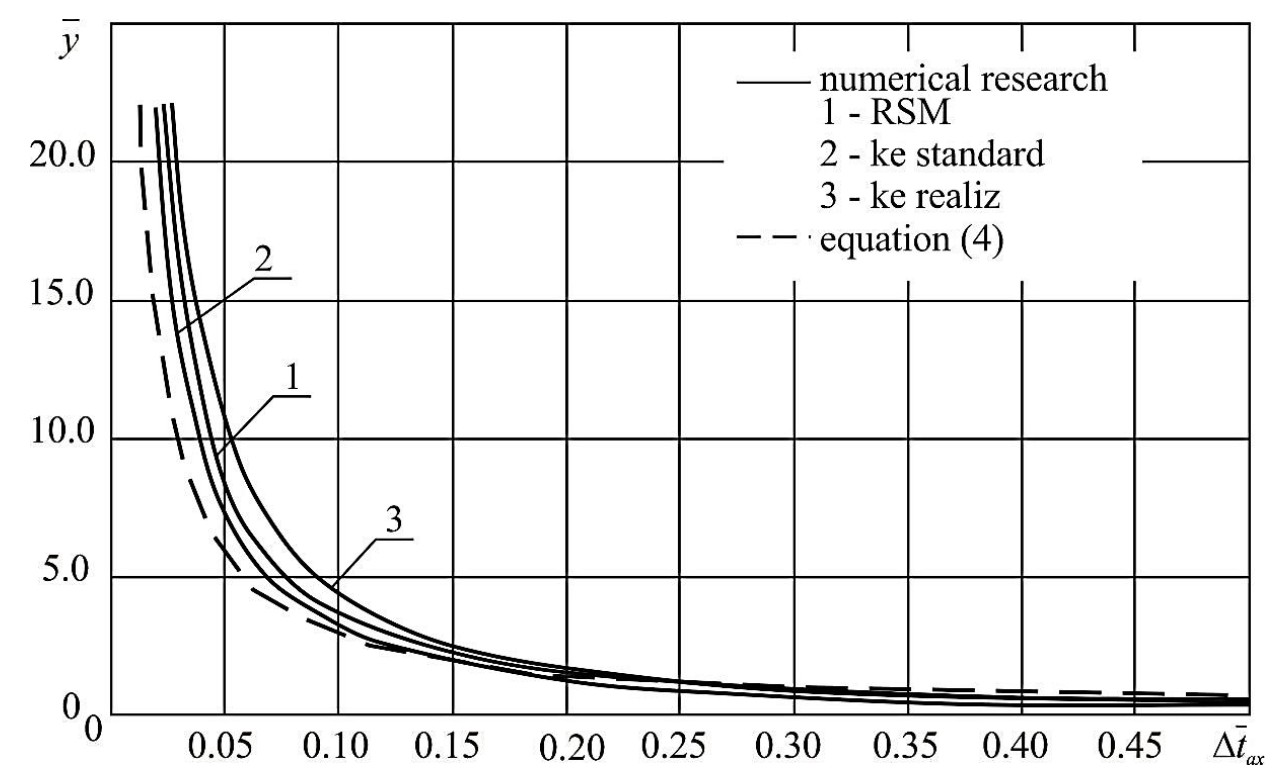

Fig. 3. The change in excess temperature along the jet height calculated using different turbulence models. 


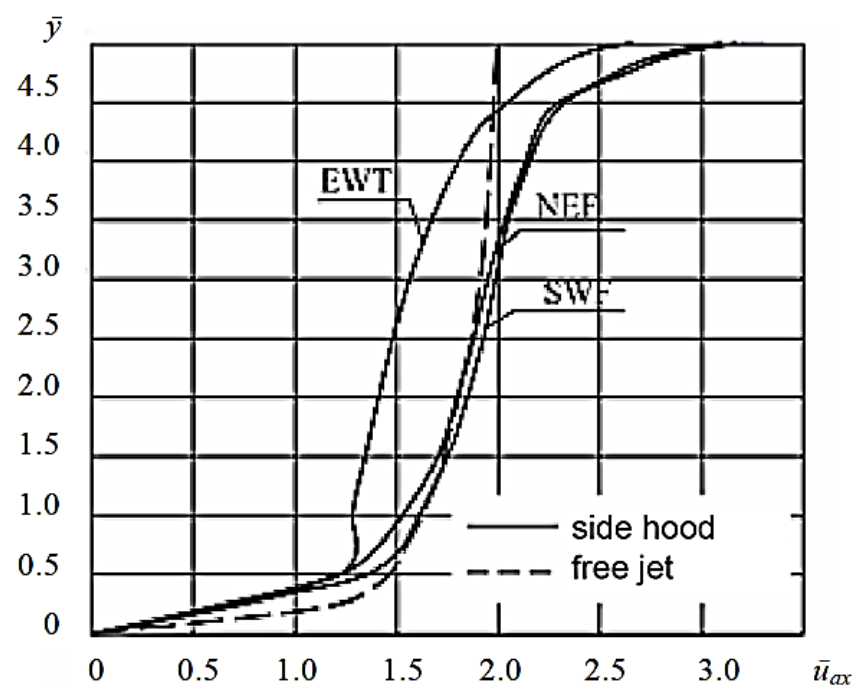

Fig.4 The change in axial velocity along the jet height calculated using different wall functions.

As in the previous case, the axial velocity of the convective jet (maximum velocity in sections), which develops near the side hood, has been determined. Figure 4 shows the change in jet velocity calculated using different wall functions. To compare the results obtained, we added a curve for the axial velocity of a free convective jet. The closest results are obtained using standard and non-equilibrium wall functions.

\section{Conclusions}

The performed numerical study considered all variants of turbulence models when considering a free convective jet and variants of wall functions. The results showed that the closest to theoretical results were those obtained when the standard k-e model together with the standard wall functions were used.

This model of numerical solution will be further used to study various options of side hoods near a heat source.

\section{References}

1. A. G. Sotnikov, A. G. Borovitsky, Systematization and generalization of local exhaust devices characteristics - the basis for engineering design techniques of effective industrial ventilation, Magazine of civil engineering (2012) DOI: 10.5862/MCE.32.8

2. A. G. Sotnikov, A. A. Borovitskiy, Theoretical and experimental validation of the air changes in industrial ventilation optimization method, Magazine of civil engineering, (2012) DOI: 10.5862/MCE.28.5

3. Z. Sajad, S. Yaser, H. Hossein, B. Mokhles, K. Masoumeh, H. Rasoul, Designing, Constructing and Installing a Local Exhaust Ventilation System to Minimize Welders' Exposure to Welding Fumes, Archives of Hygiene Sciences, 6(4), 356-652 (2017) DOI: 10.29252/ArchHygSci.6.4.356

4. A. M. Ziganshin, V. N. Posohin, A. Yu. Gorokhova, About natural convection over horizontal heat sources (2016) 
5. V. N. Posokhin, A. M. Ziganshin, S. V. Romanov, Numerical study of convection above a volumetric deep extended heat source (2011)

6. C. Bartoli, Free convection enhancement between inclined wall and air in presence of expired jets at temperature difference of 40K, Experimental Thermal and Fluid Science (2011) DOI :10.1016/j.expthermflusci.2010.09.010

7. V. N. Korovkin, A. P. Andrievskii, Turbulent free-convective jets: Numerical solution of model equations of transfer, J. Eng. Phys. Thermophys (2000) DOI: 10.1007/BF02681804

8. K. Logachev, A. Ziganshin, O. Kryukova, O. Averkova, I. Kryukov, A. Gol'tsov, Improving dust capture efficiency with local exhaust hoods in manicure shop, Building and Environment (2020) DOI :10.1016/j.buildenv.2020.107124

9. K. I. Logachev, O. A. Averkova, A. M. Ziganshin, O. S. Kryukova, V. A.Uvarov, A. B. Goltsov, Simulation of air flows at the entrance to local ventilation suction in the form of bells (2019)

10. K. I. Logachev, O. A. Averkova, A. M. Ziganshin, O. S. Kryukova, V. A. Uvarov, A. B. Goltsov, Numerical simulation of the motion of dust particles near the side suction channel (2019)

11. A. Davidov, J. Kareeva, R. Gabdrafikov, A study of the source-sink system with uneven suction. IOP Conference Series: Materials Science and Engineering, 890, 012166 (2020) DOI :10.1088/1757-899X/890/1/012166

12. P. I. Kilin, Research of regularities of detrimental impurities' diffusion propagation (2011)

13. D. Pagukuman, B. Norerama, A. Leman, M. Yusof, M. Zainal, The Efficacy of Local Exhaust Ventilation (LEV) System Controls on Aerosols Exposures during Aluminium Cans, Production Applied Mechanics and Materials, 465-466, 438-442 (2013) DOI: 10.4028/www.scientific.net/AMM.465-466.438

14. Y. Wang, M. Quan, Y. Zhou, Y. Cao, Ch. Xie, L. Li, Experimental study on the flow field and economic characteristics of parallel push-pull ventilation system (2020) DOI: 10.1016/j.enbenv.2020.03.006

15. K. Liu, Sh. Yang, L. Zeng, J. Gao, Y. Hou, Ch. Cao, B. Shi, X. Mo, Q. Zhang, Ch. Hou, Combining push-pull airflow and top draft hood for local exhaust of tyre vulcanization process (2020) DOI: 10.1016/j.enbenv.2020.04.008

16. V. A. Pankov, Influence of the scheme of organization of air exchange in the room on the efficiency of the exhaust hood (2020)

17. Fluent Inc Discrete Phase Modelling ANSYS FLUENT User's Guide (2016)

18. N. S. Surikova, Special aspects of calculation of ventilation hoods (2018)

19. I. A. Shepelev, Aerodynamic of indoor air (1978)

20. M I. Grimitlin, Indoor air distribution (1994) 